\title{
DE LA AUTONOMÍA PERSONAL AL CONSENTIMIENTO INFORMADO Y LAS VOLUNTADES ANTICIPADAS $I^{1}$
}

\section{FROM PERSONAL AUTONOMY TO INFORMED CONSENT AND ADVANCED DIRECTIONS}

\section{Víctor M. MARTÍNEZ BULLÉ GOYRI ${ }^{2}$}

\section{Alexandra OLMOS PÉREZ ${ }^{3}$}

RESUMEN: En este trabajo se aborda cómo los individuos hemos logrado en los últimos tiempos el respeto a nuestra dignidad en el momento de la muerte, ejerciendo nuestra autonomía al asumir decisiones con relación a la manera en que queremos vivir el tránsito de la vida a la muerte, si bien no tomando el control sobre el momento mismo de la muerte, sí sobre las condiciones y la atención médica que deseamos nos sea proporcionada en ese momento. Desde el punto de vista jurídico se ha desarrollado la idea de que tratar a un paciente sin su consentimiento o pese a sus objeciones puede constituir una conducta antijurídica. Al derecho de la persona de autodeterminarse se corresponde el deber del médico de informar al paciente la verdad sobre su condición, los cursos de acción entre los cuales puede elegir, sus consecuencias, de manera que cuente con los medios para poder adoptar una decisión. El derecho a la información y al consentimiento informado se han desarrollado como un derecho autónomo, complementario al derecho a la salud. La doctrina del consentimiento informado dio lugar a que se empezara a reconocer el derecho que tenemos todos a tomar decisiones con respecto al final de nuestra propia vida. Vivir con dignidad ese momento significa, entre otras cosas, además de la eliminación del dolor y el sufrimiento, que se respete nuestra autonomía; esto es, nuestra voluntad sobre qué tipo de atención médica queremos recibir y hasta qué momento queremos recibirla. El paso siguiente sería encontrar el medio más adecuado para que esa voluntad pudiera expresarse, siendo que y es así como surgen las llamadas "voluntades anticipadas", que actualmente forman ya parte del sistema jurídico mexicano en diversas entidades federativas, y lo cual ha llevado al desarrollo de un nuevo ámbito de servicios médicos para

\footnotetext{
${ }^{1}$ Este artículo constituye la primera parte de un texto más amplio. En la segunda parte se desarrollará la implementación de las voluntades anticipadas en el derecho mexicano, que por razones de espacio fue imposible incluir aquí.

${ }^{2}$ Investigador titular de tiempo completo en el Instituto de Investigaciones Jurídicas de la UNAM.

${ }^{3}$ Directora académica en el Instituto de Formación e Investigación en Bioética y Bioderecho.
} 
Esta revista forma parte del acervo de la Biblioteca Jurídica Virtual del Instituto de Investigaciones Jurídicas de la UNAM

los pacientes terminales: los cuidados paliativos, que ya se encuentran previstos también a nivel federal en la Ley General de Salud.

Palabras clave: dignidad, autonomía, consentimiento, información, salud, voluntad anticipada, cuidados paliativos.

ABSTRACT: This paper addresses how individuals have recently achieved the idea of respect and dignity at the end of life, exercising their autonomy to take decisions about the way they want to live the passage from life to death, if not by taking control over the time of death, but regarding the conditions and care to be provided at that time. From the legal point of view we have developed the idea that treating a patient without his consent or despite his or her objections may constitute an unlawful conduct. The right of selfdetermination of the person is matched with the duty of the physician to inform the patient the truth about his condition, the courses of action from which to choose, its consequences, and also provide him or her with the means to adopt his or her decision. The right to information and informed consent has been developed as an autonomous right, complementary to the right to healthcare. The doctrine of informed consent led us to recognize the right we all have to make decisions about the end of our own life. To live with dignity means, among other things, in addition to the elimination of pain and suffering, that our autonomy is respected, this is our will on what medical care we receive and until when we want to receive it. The next step would be to find the most appropriate means for that will to be expressed, which is why we developed the so called advanced directions, which are currently a part of the Mexican legal system in various states, and which has led to the development of a new field of health care for terminal patients: palliative care, which are already provided also at the federal level in the General Health Law.

Keywords. Dignity, Autonomy, Consent, Information, Health, Advanced Directions, Palliative Care.

SUMARIO: I. Introducción. II. Los inicios de la ética médica: el paternalismo. III. La aparición de la figura del consentimiento informado en la relación médico-paciente. IV. El respeto de la autonomía en la bioética. V. Bibliogafía.

\section{INTRODUCCIÓN}

En toda la historia de la humanidad el principio y el fin de la vida han sido considerados acontecimientos, más allá del hecho físico, de profundo significado e importancia para la existencia personal, y con grandes repercusiones en el entorno familiar y social. Con ellos se inicia y termina la historia individual de cada uno en cuanto a la existencia en este mundo $y$, curiosamente, no obstante que se trata tal vez de los dos acontecimientos 
más importantes de nuestra vida, hemos participado siempre en ellos casi en condición de espectadores, sin importar que seamos los verdaderos protagonistas. Nacimiento y muerte han sido así hechos fatales, ajenos a nuestra voluntad.

Respecto de la fecha, del momento, de las condiciones y de las circunstancias de nuestro nacimiento, nada tenemos que decir, pues carecemos en su momento de las capacidades necesarias para expresar nuestra opinión sobre el hecho; más aún: ni siquiera conservamos el recuerdo del momento en nuestra memoria consciente. Así se inicia nuestra vida, en condición de dependencia absoluta a la voluntad de otros, que son quienes tomaron la decisión sobre nuestra existencia. Nuestras capacidades intelectuales, la libertad y nuestra condición de entes morales tardarán meses o incluso años en años en aparecer. Inicialmente nuestra dignidad depende única y exclusivamente de nuestra condición humana. Nuestra vida e individualidad son sólo objeto de tutela y protección por los demás.

Al final de nuestra existencia, normalmente después de una larga vida, ya con nuestras capacidades intelectuales y volitivas desarrolladas por completo y ejercidas en multitud de momentos relevantes, decidimos, entre otras cosas, a qué profesión dedicarnos, en dónde vivir, con quién o quiénes compartimos nuestra vida, si formamos y con quién una familia, si somos útiles o no a la sociedad; pero a pesar de todo eso, cuando la vida está por terminarse nos encontramos de nuevo ante un hecho fatal, ajeno a nuestra voluntad, postrados casi como objetos ante el médico, que es quien históricamente ha asumido la adopción de las decisiones con relación a los últimos momentos de la vida de las personas.

En este trabajo pretendemos desarrollar precisamente cómo los individuos hemos logrado en los últimos tiempos el respeto a nuestra dignidad en el momento de la muerte, al asumirla de acuerdo con nuestra condición de entes morales, ejerciendo nuestra autonomía al asumir decisiones con relación a la manera en que queremos vivir el tránsito de la vida a la muerte. Si bien no tomando el control sobre el momento mismo de la muerte, como sucede con el caso de la eutanasia a solicitud del enfermo o con el suicidio, que son temas cuya moralidad es motivo de profundas discusiones y divisiones en la sociedad, sí sobre las condiciones y la atención médica que deseamos nos sea proporcionada en ese momento, quitando al personal médico protagonismo y responsabilidades. 
En la actualidad podemos decir que existe, en términos éticos, morales, deontológicos y jurídicos, una obligación por parte del personal de salud, de informar a la persona que requiere sus servicios en calidad de paciente, o bien a quien haya de tomar una decisión que tenga consecuencias en la salud de dicha persona, acerca de su salud o su situación concreta desde el punto de vista médico, así como las diversas opciones que existen de atención y tratamiento. Y, por supuesto, una vez entablada esa comunicación, la obligación de respetar plenamente las decisiones que en ese sentido sean tomadas por la persona o su legítimo representante siendo ejes rectores en todo momento principios como son respeto, información, comunicación, consentimiento, minimizar riesgos, potencializar beneficios, justa distribución de cargas y beneficios, no discriminación, no maleficencia, transparencia, seguridad, inclusión e integración cultural, entre muchos otros. Hoy entendemos que

Respetar la autonomía es dar valor a las opiniones y elecciones de las personas así consideradas y abstenerse de obstruir sus acciones, a menos que éstas produzcan un claro perjuicio a otros. Por el contrario, mostrar falta de respeto por un agente autónomo es repudiar los criterios de estas personas, negar a un individuo la libertad de actuar según tales criterios o hurtar información necesaria para que pueda emitir un juicio, cuando no hay razones convincentes para hacerlo. ${ }^{4}$

Asimismo, avanzamos cada vez más como sociedad hacia el reconocimiento del derecho que tiene toda persona, en virtud de su autonomía, a decidir o rechazar tratamientos, procedimientos o intervenciones de carácter médico, especialmente al enfrentarse con el final de su vida, decisión que deberá ser respetada por el médico, pero también por la familia y seres queridos del paciente, quien es el indiscutible titular de sus derechos.

No obstante, la lógica actual que permea las relaciones entre el personal de salud, especialmente desde el punto de vista propio del médico, con el paciente y la sociedad, desde un punto de vista tanto jurídico como ético, es resultado de todo un desarrollo histórico, que integra elementos sociales, económicos, políticos, filosóficos, jurídicos, que han generado actualmente la posibilidad de discutir los derechos de los pacientes desde un nuevo paradigma de atención médica, de una concepción distinta de la profesión médica en sí.

\footnotetext{
${ }^{4}$ Abellán, Fernando y Sánchez-Caro, Javier (coords.), Medicina genética clínica del siglo XXI. Consideraciones científicas, éticas y legales, Madrid-Granada, Comares, 2009, p. 154.
} 


\section{LOS INICIOS DE LA ÉTICA MÉDICA: EL PATERNALISMO}

La salud y su conservación han ocupado siempre un lugar preponderante en la vida de las personas y en la sociedad; por eso, quienes se han dedicado a la atención de la salud de los demás han gozado a lo largo de la historia, de gran prestigio y reconocimiento social, y a la persona del médico, sanador o curandero se le reconoce una autoridad moral altísima, que en ciertos momentos de la historia elevó a su profesión a un nivel casi sacerdotal; ante su figura y autoridad el enfermo era incapaz física y moralmente, por lo que el médico debía decidir por él diciéndole lo que era mejor, con la finalidad de conservar su salud y prolongar su vida mediante la cura de la enfermedad.

Desde el punto de vista de la historia del pensamiento universal, todos los saberes, las artes y los oficios tuvieron un origen común en la filosofía, que en sus inicios vinculaba a todos los fenómenos en el orden supremo de la physis. Dicho orden tenía un carácter además normativo, puesto que constreñía, en la lógica del pensamiento clásico, a su conservación $y$, en caso de ser violentado, a su restauración. Éste fue el papel primario de la ética, que en ese contexto es denominada como naturalista. En tal sentido, el conocimiento de esa verdad constituida por el orden supremo era el estándar regulador también de la conducta humana, y el telos del hombre estaba definido e integrado en su propio ser.

Dentro de esa misma secuencia de pensamiento es que surge la figura del médico como guardián de dicho orden y, por lo tanto, la techné que practicaba el médico tuvo un papel casi sagrado; es la medicina la actividad ética por excelencia, y uno de los elementos centrales de la cultura occidental. El paternalismo fue, así, inherente a la práctica de la medicina, puesto que es definido desde la percepción del médico como guardián de algo tan sagrado que ni siquiera puede dejarse en manos de su titular o propietario, que es el orden natural, el equilibrio, e incluso el ser mismo del hombre.

Durante la mayor parte de la historia de la medicina, desde la antigüedad hasta hace apenas unas décadas, el médico consideró al paciente o infirmus -que significa "no firme"- como débil y sin capacidad para hacer frente a la enfermedad, fundamentalmente por la falta de conocimientos sobre sus causas y sobre el funcionamiento de su propio organismo, por lo que asumió una actitud paternalista, en la que no se tomaba en cuenta lo que el enfermo quería, sino lo que el médico 
consideraba como mejor para él. El juramento hipocrático es el típico ejemplo del médico paternalista, que ubica su deber por encima de la voluntad del paciente. ${ }^{5}$

El paternalismo médico se caracteriza por la idea de que el médico maneja bienes tan precisados - la salud y la vida- que pueden incluso considerarse sagrados. Así, cuando el médico juraba hacer el bien, se entendía que la lucha por ese bien podía ser incluso contra la voluntad misma del paciente.

El carácter mismo de esta sacralización del arte de la medicina, la autoridad no solamente técnica o científica, en el sentido clásico de la palabra, sino también moral del médico, está plasmada en uno de los códigos dentológicos más antiguos que existen en relación con la práctica médica, como es el juramento hipocrático, y que la comprensión así del rol del profesional de la salud en el mundo occidental funciona como elemento toral de cohesión al interior del gremio.

A esta gestante tradición se integraron, al punto de no poder en ocasiones llegar a disgregarse sin afectar la comprensión misma de esta profesión, los mandatos de las religiones monoteístas, como el cristianismo, cuya doctrina de compasión, amor al prójimo y, por supuesto, caridad, influyó de manera innegable en el pensamiento y en la cultura occidental en todas las áreas del conocimiento de igual manera, hasta llegar a formar parte irrenunciable de ellas. ${ }^{6}$

Con la profesionalización de la medicina en la Edad Media, se generaron los requerimientos académicos y legales para su ejercicio, así como la aparición de las facultades de medicina y las licenciaturas académicas o licencias estatales, e instituciones destinadas a la formación en medicina, que daban prestigio al ya consolidado gremio, y en donde surgieron estatutos propios hacia el interior de su organización. ${ }^{7}$

\footnotetext{
5 “No administraré a nadie un fármaco mortal, aunque me lo pida...".

${ }^{6}$ Pavía-Ruz, Norma et al., "Magia, religión y medicina”, Revista Biomédica, núm. 9, 1998, pp. 192-198; Campagne, Fabián Alejandro, "Medicina y religión en el discurso antisupersticioso español de los siglos XVI a XVIII: un combate por la hegemonía", Dynamis: acta hispanica ad medicinae scientiarumque historiam illustrandam, Granada, Universidad de Granada, núm. 20, 2000, pp. 417-456.

${ }^{7}$ Barquín Calderón, Manuel, Historia de la medicina, 8a. ed., México, Méndez Editores, 2007.
} 
Esta revista forma parte del acervo de la Biblioteca Jurídica Virtual del Instituto de Investigaciones Jurídicas de la UNAM

Hasta ahora, el pensamiento ético había girado en torno a la idea del bien, de la virtud, de la calidad ética del acto o la calidad ética del sujeto. Pero fue el siglo XVIII parteaguas en la filosofía moral a partir del pensamiento de Immanuel Kant. Al respecto, dice Jerome Schneewind:

En el núcleo de la filosofía moral de Emmanuel Kant está la afirmación de que la moralidad se centra en una ley que los seres humanos se imponen a sí mismos, y que al hacerlo necesariamente se proporcionan un motivo para obedecer. Kant llama autónomos a los agentes que se autogobiernan de este modo. Es un término que tomó del pensamiento político de los siglos XVII y XVIII, en los que se empleaba cuando se hablaba de la idea de los Estados como entidades que se autogobiernan. He apuntado que la idea del autogobierno se remonta por lo menos a la aseveración de san Pablo en Romanos 2.14 de que los gentiles "para sí mismos son ley". Kant entendió la idea de una forma radicalmente diferente. Su opinión sobre la moralidad como autonomía es algo nuevo para la historia del pensamiento. ${ }^{8}$

Kant apuesta por el valor de la libertad no solamente como causa, sino como fundamento de la moralidad y la ética. La filosofía moral hasta entonces prácticamente daba por hecho la libertad, y atribuía el valor de la acción moral a elementos externos; es decir, que la norma moral tenía un fundamento heterónomo, puesto que era la naturaleza o la voluntad divina el estándar de corrección o de verdad en el terreno de la ética. Rizieri Frondizi lo explica así:

El pensamiento griego poco contribuyó al problema de la libertad y el Medioevo lo trató, con frecuencia, en relación al problema teológico. Entonces, la preocupación era: ¿cómo se puede reconciliar la libertad humana con la omnisapiencia y la omnipotencia divina? En cambio, Kant, se interesó por la compatibilidad entre la libertad y el principio de causalidad que rige en el mundo natural, y llega así a su concepción de la causalidad libre, que tiene vigencia en el plano moral. Kant está convencido de que la moralidad es imposible sin la libertad. $^{9}$

Es así que, en palabras del autor, "Kant se dirige hacia una nueva idea de la relación que hay entre la voluntad y el bien. Ya no piensa que la voluntad procura solamente

\footnotetext{
${ }^{8}$ Schneewind, Jerome B., La invención de la autonomía. Una historia de la filosofía moral moderna, México, Fondo de Cultura Económica, 2009, p. 571.

${ }^{9}$ Frondizi, Rizieri, Introducción a los problemas del hombre, 2a. ed., México, Fondo de Cultura Económica, 2004, p. 80.
} 
Esta revista forma parte del acervo de la Biblioteca Jurídica Virtual del Instituto de Investigaciones Jurídicas de la UNAM

aquello que se presenta como bueno", ${ }^{10}$ sino que invierte el esquema, apelando a la capacidad racional de todos los seres humanos.

Por ello, dice García Morente, Kant

...nos abre ya una pequeña puerta fuera del mundo de los fenómenos, fuera del mundo de los objetos a conocer, fuera de la tupida red de condiciones que el acto de conocimiento ha puesto sobre todos los materiales con que el conocimiento se hace. Porque si la voluntad moral pura es voluntad autónoma, entonces esto implica necesaria y evidentemente el postulado de la libertad de la voluntad. ${ }^{11}$

La idea en que se había basado la ética socrática, de que la voluntad de conocer nos acerca a la idea del bien, que identifica bien con verdad, que había sido cimiento para la ética de la virtud y la ética material de bienes, como es el caso de las éticas utilitaristas, apuntaban desde lo externo para guiar la conducta del hombre.

La ética kantiana reside en la voluntad del individuo, que es lo único esencialmente bueno: "es la voluntad la que ocasiona la moralidad", ${ }^{12}$ y no solamente eso, sino que como consecuencia, “la razón práctica, la conciencia moral y sus principios tienen la primacía sobre la razón pura... Por consiguiente, todo el conocimiento es un conocimiento puesto al servicio de la ley moral". ${ }^{13}$ El carácter apriorístico de la moralidad, basada en la libertad de la voluntad, es entonces una consecuencia del planteamiento kantiano de la ética; el deber es fundamento y fin de la ética, porque es impuesto por la voluntad, "es la necesidad de actuar conforme a la ley moral". ${ }^{14}$

Fue por este nuevo paradigma de pensamiento que la postura paternalista en relación con el rol del médico fue matizada. Especialmente podemos mencionar el pensamiento del médico inglés del siglo XVIII, Thomas Percival, cuya obra Medical ethics es considerada el texto fundacional de la deontología médica y origen de los posteriores códigos de ética, en la que plantea que el médico debe ser un verdadero caballero, un hombre bueno, que inspire la confianza del paciente, respecto del cual asume

\footnotetext{
${ }^{10}$ Schneewind, Jerome B., op. cit., p. 590.

${ }^{11}$ García Morente, Manuel, Lecciones preliminares de filosofía, 18a. ed., México, Porrúa, 2005, p. 233.

${ }^{12}$ Schneewind, Jerome B., op. cit., p. 604.

${ }^{13}$ García Morente, Manuel, op .cit., p. 237.

${ }^{14}$ Frondizi, Rizieri, op. cit., p. 70.
} 
plenamente la responsabilidad, pero sujeto a la idea de beneficencia más que a la del respeto de la autonomía del paciente, que en la época no era realmente concebible todavía, ${ }^{15}$ como puede verse en sus palabras, que años después fueron incluidas en el primer código de ética de la Asociación Médica Norteamericana de 1847: “Médicos y cirujanos deben servir al enfermo reflejando que el alivio, la salud y la vida de aquellos asignados a su cuidado dependen de sus habilidades, atención y fidelidad. Ellos deberían comportarse con ternura, firmeza y condescendiente autoridad para inspirar en sus pacientes, gratitud, respeto y confianza". ${ }^{16}$

Algunos autores, como Diego Gracia, consideran que Percival propuso un paternalismo más moderado, al que llama "juvenil", al menos respecto de la obligación de informar verazmente al enfermo respecto de su condición, aunque sostenga que en los casos de las enfermedades graves o mortales debía dar la información a los familiares del enfermo, para que fueran ellos los que lo comunicaran al paciente. ${ }^{17}$ Desde nuestro punto de vista, esto no constituye un mayor respeto al paciente, sino una forma de proteger la autoridad del médico, que en gran medida se funda también en la esperanza de que mediante sus conocimientos y capacidades podrá curar al enfermo.

En esta etapa la relación médico-paciente implicaba para éste el sometimiento y abandono total en la experiencia del médico, situación que se fortaleció a raíz de la profesionalización del ejercicio de la medicina y la formalización de los estudios médicos, y tendrían que pasar muchos años para que se comenzara a tomar realmente en cuenta la voluntad del paciente y se diera importancia al respeto a su autonomía como expresión de su dignidad.

Fue el pensamiento kantiano piedra angular de la filosofía moderna, y su imperativo categórico, emblema del pensamiento ilustrado. El impacto que tuvo hizo estruendo también en la concepción de la profesión del médico, y es así que en los Estados Unidos

\footnotetext{
15 http://WWw.elabe.bioetica.org/34.htm, capítulo IX, "La deontología profesional", y http://eticabioetica.obolog.com/rol-leyes-codigos-eticos-practica-clinica-215346.

16 Drave, James F., “La ética como carácter y la investigación médica”, Acta Bioethica, Organización Panamericana de la Salud, año X, vol. X, núm. 1, p. 21.

${ }^{17}$ Gracia, Diego, Fundamentos de bioética, 3a. ed., Madrid, Triacastela, 2008, p. 91.
} 
Esta revista forma parte del acervo de la Biblioteca Jurídica Virtual del Instituto de Investigaciones Jurídicas de la UNAM

en el siglo XVIII surgieron las ideas de dos grandes teóricos: Benjamín Rush ${ }^{18}$ y John Gregory $^{19}$ quienes sostuvieron que dentro de las tareas del médico estaba la de dar al enfermo acceso a la información en relación con su condición médica, considerando que esto habría de beneficiarlo, aunado a que en la lógica del libre mercado el que paga manda, mientras que, hasta este momento, en la práctica de la medicina funcionaba justo al contrario, el que pagaba obedecía, y el poder se encontraba concentrado en el monopolio de los médicos. Especialmente Gregory fue un gran precursor del libre mercado en el ejercicio de la profesión médica y la abolición del monopolio de la profesión.

Uno de los pensadores más emblemáticos en torno a la idea del "beneficio terapéutico", que facultaba al médico a ocultar información al paciente si consideraba que el despliegue de ésta podría perjudicar su salud, fue Worthington Hooker. En su obra publicada en 1849, intitulada Physician and Patient, se opone abiertamente al pensamiento de Percival, sin negar que exista información que efectivamente pueda dañar al paciente lejos de hacerle cualquier bien, pero señalando que por ningún motivo debía engañarse al paciente o caer en falsedad, y manifiesta que el deber del médico debe ser enfocarse en la perspectiva del paciente y su necesidad de información:

Moral truth, in a professional view, has two references; one to the party to whom it is delivered, and another to the individual by whom it is uttered. In the first it is a relative duty, constituting a branch of justice, and may properly be regulated by the divine rule of equity prescribed by our Saviour, to do unto others as we would, all circumstances duly weighted, they should do unto us. In the second, it is a relative duty, regarding solely the sincerity, the purity and the probity of the physician himself. To a patient, therefore perhaps the father of a numerous family, or one whose life is of the highest importance to the community, who makes inquiries, which, it faithfully answered, might prove fatal to him, it would be a gross and unfeeling wrong to reveal the truth. His right to it suspended, and even annihilated; because its beneficial nature being reversed, it would be deeply injurious to himself, to his family, and to the public. And he has the strongest claim, from the trust reposed in his physician, as well as from the common principle of humanity, to be guarded against

\footnotetext{
${ }^{18}$ Rush, Benjamin, “Estudio de la influencia de las causas físicas sobre la facultad moral”, Psiquiatría.com, vol. I, núm. 3, 1997; The Selected Writings of Benjamin Rush, Nueva York, Philosophical Library, 1947.

${ }^{19}$ Strätling, M., "John Gregory (1724-1773) and his lectures on the duties and qualifications of a physician establishing modern medical ethics on the base of the moral philosophy and the theory of science of the empiric British Enlightenment", Medicina nei Secoli, vol. 9, núm. 3, 1997, pp. 455-475.
} 
whatever would be detrimental to him... but I do not agree with him [Percival], that in withholding the truth we have the right to put absolute falsehood in its place... The obvious rule on this subject is this -that the truth should not be withheld unless there be a reasonable prospect of effectually preventing a discovery of it, and that too by fair and honest means. ${ }^{20}$

A lo que se opone Hooker no es a retener información, puesto que concibe todavía a los derechos del paciente desde un punto de vista de la beneficencia, y no de la autonomía y la libertad, sino a incurrir en falsedad. Entiende que como deber prima facie el médico está obligado a informar al paciente, pero que si existen circunstancias —que no son necesariamente relacionadas con su salud, lo cual también aporta a ampliar el espectro de consideración por parte del médico- que pudieran implicar que el despliegue de información pudiera perjudicar al paciente, entonces estará facultado para retener la información, pero sin llegar a caer en engaño o falsedad; es decir, que deberá conducirse éticamente incluso al llevar a cabo esa retención.

Como podemos ver, no ha sido abandonada la idea del médico paternalista por completo, puesto que aún no se concibe al acceso a la información como un derecho del sujeto por respeto a su autonomía, sino como un elemento susceptible de beneficiar al paciente. $Y$ respecto del derecho a la información, hay un largo trecho que caminar hacia la consolidación del derecho a la autodeterminación en el ámbito biomédico. No obstante, es innegable un avance desde Kant hacia un enfoque de la ética basada en el respeto a la dignidad humana y la autonomía de la voluntad, que habría de consolidarse con el desarrollo del liberalismo y el individualismo, que también impactaron en el universo de lo jurídico en la construcción de los derechos desde esa perspectiva.

\section{LA APARICIÓN DE LA FIGURA DEL CONSENTIMIENTO INFORMADO EN LA RELACIÓN MÉDICO-PACIENTE}

Esta milenaria tradición del médico paternalista empezó a transformarse, a partir del siglo XX, en una actitud de respeto por la dignidad y la libertad de las personas, expresada en lo que se ha denominado la autonomía del paciente dentro de las relaciones médico-asistenciales.

\footnotetext{
${ }^{20}$ Hooker, Worthington, "Truth in Our Intercourse with the Sick", extracto de la obra Physician and Patient, en Beauchamp, Tom L. y Walters, Leroy, Contemporary Issues in Bioethic, 3a. ed., Estados Unidos, Wadsworth Publishing Company, 1989, pp. 377-380. Los corchetes son del autor.
} 
Es importante resaltar que el respeto a la autonomía personal les fue impuesto a los médicos desde la tradición ética jurídica, y en gran medida como un desarrollo de la teoría de los derechos humanos, puesto que se trata de una idea ajena a sus prácticas históricamente hablando, y como resultado del pensamiento liberal que postula la separación de la moral pública y la moral privada, de donde surge la idea de privacidad o intimidad como un ámbito en el cual ni el Estado ni los demás miembros de la sociedad deben tener injerencia, como expone John Stuart Mill.

El individualismo liberal, que buscaba afirmar a la persona como un ente diverso y separado de la colectividad, dio como resultado el surgimiento de la economía de mercado, en la que no solamente se tiene un libre acceso a los productos y servicios, sino que además se reconoce el poder de decisión a la persona que paga por ellos y, dado que la profesión del médico había empezado a perder su carácter sacerdotal de corte beneficentista, equiparándose a una prestación de servicios a cambio de un pago, la relación médico-paciente empezó a regirse por esta lógica, que obliga al médico a obedecer las órdenes del paciente, que es la persona que paga por sus servicios, lo cual de cierta forma abonó a su "emancipación".

Podemos acercarnos a la idea de una medicina liberal, recordando el célebre pasaje que sintetiza el planteamiento de Mill en torno a la legitimación de las intervenciones de terceros en la vida privada de los individuos:

...la propia defensa es el único fin que autoriza a la humanidad, ya sea individual o colectivamente, a intervenir en la libertad de acción de cualquiera de sus miembros; que el poder sólo puede ejercerse con todo derecho contra la voluntad del cualquier miembro de una comunidad civilizada, cuando se trata de evitar daños a otros. Ni siquiera es razón suficiente el propio bien físico o moral del individuo. No hay derecho alguno para obligarlo a actuar o dejar de hacerlo, porque sea para su propio bien, porque con ello pueda ser más feliz, o porque, en opinión de los demás, hacerlo sería más recomendable o aun justo. ${ }^{21}$

En tal sentido, dice Roberto Nogueira que la medicina liberal es aquella que se define como "la que ejerce cada profesional con autonomía técnica y económica en las clínicas y los consultorios particulares", y que "está libre de los lazos de subordinación a una autoridad o a un jefe y porque se basa en la libre elección por parte de los pacientes"; es

${ }^{21}$ Mill, John S., Sobre la libertad, 5a. ed., México, Gernika, 2006, p.20. 
decir, que el ejercicio de la profesión se volvió autónomo "en lo que se refiere a la propiedad de los medios de trabajo y a la clientela que se beneficia de sus servicios". ${ }^{22}$

Estas teorías empezaron a verse reflejadas en la legislación estadounidense, que estableció las figuras de malpractice o negligencia médica, battery o coacción o intervención no consentida y el informed consent o consentimiento informado, que fueron creadas para controlar la actividad del médico en relación con el paciente.

Hoy en día el concepto de consentimiento ha evolucionado desde el punto de vista de la ética médica de la exigencia de un consentimiento simple para actuar sobre un individuo, que ahora incluye no nada más la obligación de "avisar" al paciente previo a la realización de un procedimiento o simplemente dejarle la decisión y en todo caso actuar o no, y se integra al concepto una noción procedimental y dialógica, en la que es fundamental establecer condiciones que posibiliten de manera óptima el diálogo en el contexto biomédico, tomando en cuenta que habrán de respetarse en todo momento las opiniones, sentimientos y preocupaciones propias de la esfera cultural que acompaña a todo individuo, y la asunción de un verdadero compromiso para un intercambio de información oportuna, veraz, clara y suficiente, con miras a la consolidación de una relación no solamente profesional o de prestación de servicios, sino confidencial -en todo el sentido de la palabra confianza-, y que no se agota en un solo momento, sino que persiste durante todo el tiempo que dure la interacción del médico con el paciente.

Tomando en cuenta que dicho concepto, como resultado de la reflexión ética, surge del dinamismo de las sociedades humanas, y siendo que el derecho no solamente es el instrumento institucionalizador de los mandatos éticos a través de normas, sino que aporta como herramienta de cambio social a la construcción de nociones éticas y percepciones de los valores, podemos apreciar que desde el punto de vista jurídico se ha desarrollado la idea de que tratar a un paciente sin su consentimiento, o pese a sus objeciones, puede constituir una conducta antijurídica.

El mandato ético de libertad es también fundamento del orden jurídico en todo sistema con pretensiones democráticas, y podríamos decir que actualmente entendemos que el papel mismo del derecho es precisamente potencializar las posibilidades de alcanzar una vida humana, en todo sentido, lo cual implica que, si bien establece límites

\footnotetext{
${ }^{22}$ Nogueira, Roberto P., "La medicina liberal y el mercado de trabajo en salud ¿Qué es la medicina liberal?", Revista Educación Médica y Salud, vol. 22, núm. 2, 1988, p.145.
} 
Esta revista forma parte del acervo de la Biblioteca Jurídica Virtual del Instituto de Investigaciones Jurídicas de la UNAM

a nuestra libertad, lo hará siempre y cuando sea con la finalidad última de posibilitarla para todo individuo inmerso en la vida comunitaria. ${ }^{23} \mathrm{El}$ derecho existe gracias a nuestra libertad, y a la vez nos permite descubrir nuestra libertad, puesto que nos deja hacer nuestras propias reglas, que podemos libremente obedecer o no.

Se ha dicho que la influencia, o, mejor dicho injerencia, de los juristas en el ámbito biomédico ha acentuado el carácter adversarial de la relación médico-paciente. Al respecto, dice George Annas:

The primary argument against patients' rights is that patients have "needs" and that defending these needs in terms of rights leads to the creation of an unhealthy adversary relationship. It is not, however, the creation of rights, but the disregard of them, that produces adversaries. When provider and patient work together in an atmosphere of mutual trust and understanding, the articulation of rights can only enhance their relationship. $^{24}$

La ética en el ejercicio de la profesión médica, dice Edmund Pellegrino, está constituida por un sistema de obligaciones relacionadas con el rol del médico en la sociedad, y que pueden ser ubicadas en tres niveles de acuerdo con el grado de sensibilidad ética que persiguen: la observancia de las normas, el respeto a los derechos y el cumplimiento de los deberes, y finalmente la práctica de la virtud. El primer nivel, que sería el de una ética basada en la legalidad, sería una ética de requisitos mínimos. El segundo buscaría ir más allá de la legalidad, integrando principios como el de beneficencia, no maleficencia, autonomía, entre otros. Finalmente, el último nivel, la práctica de la virtud, se extiende más allá de la idea misma del deber, y mantiene estándares que sobrepasan los que prevalecen en los acuerdos sociales. No obstante lo anterior, Pellegrino no considera que podamos prescindir de los primeros dos niveles:

The more we yearn for ethical sensitivity the less we lean on rights, duties, rules and principles, and the more we lean on the character traits of the moral agent. Paradoxically, without rules, rights and duties specifically spelled out, we cannot predict what form a particular person's expressions of virtue will take. In a pluralistic society, we need laws,

\footnotetext{
23 "...el derecho y la ética buscan reconocer y asegurar una vida digna a los individuos de una sociedad", Carrión García, Yazmín Yadira, Derecho: fines y alcances desde la perspectiva de Fernando Savater, México, Porrúa-Facultad de Derecho UNAM, 2013, versión Kindle.

${ }^{24}$ Annas, George J., "The Emerging Stowaway: Patients' Rights in the 1980s”, en Beauchamp, Tom L. y Walters, Leroy, Contemporary Issues in Bioethics, cit., p. 335.
} 
rules, and principles to assure a dependable minimum level of moral conduct. But that minimal level is insufficient in the complex and often unpredictable circumstances of decision making, where technical and value desiderata intersect so inextricably. ${ }^{25}$

En tal sentido, el autor dice que si bien la ética clásica en el mundo occidental apuntaba hacia la práctica de la virtud -lo cual es relevante, especialmente porque es en ese paradigma donde surge la tradición médica occidental, con su respectivo ethos, vinculada estrictamente con un telos, que era el orden natural-, hoy en día, es complejo basar la actividad profesional de la medicina en ese concepto por sí solo, dada la complejidad y la pluralidad de las sociedades actuales, aunado a que conviven diversas tradiciones médicas y éticas, lo que hace complicado hablar de una sola e indivisible noción de virtud. No obstante, reconoce que la mera legalidad no es base suficiente para la ética, y que debemos de cierta manera apuntar hacia la construcción no solamente de mínimos, sino también a la consecución de máximos.

Ahora hablaremos un poco de cómo se fue construyendo esa base mínima desde el punto de vista de la legalidad, sin pensar por un momento en que se trata de una victoria absoluta a favor del respeto a la autonomía de las personas en el ámbito biomédico, pero teniendo en mente que el derecho es también un instrumento susceptible de propiciar cambios en el pensar y actuar de las sociedades.

Un primer antecedente dentro de la historia de la medicina occidental, podemos encontrarlo en el derecho anglosajón, a través de la jurisprudencia, puesto que uno de los principios fundamentales en esta tradición jurídica es que un individuo no podrá ser violentado en su privacidad, intimidad, cuerpo y pertenencias por terceros sin una razón legítima, o bien, sin su autorización o consentimiento.

En dicho sentido, la primera sentencia que se conoce referida a una negligencia médica se dictó en Inglaterra en 1767, en el caso Slater vs. Baker and Stapleton, respecto de una paciente a la que con ocasión del cambio de la curación de una fractura en una pierna fue sometida a una nueva fractura, al considerar el médico que el hueso no había soldado de forma correcta. ${ }^{26}$

\footnotetext{
${ }^{25}$ Pellegrino, Edmund D., "The Virtuous Physician and the Ethics of Medicine", en Beauchamp, Tom L. y Walters, Leroy, Contemporary Issues in Bioethics, cit., p. 320.

${ }^{26}$ Véase $h t t p: / / w w w . d i a r i o s a l u d . n e t / c o n t e n t / v i e w / 13793 / 2 /$.
} 
En el caso Slater, observa Tristam Engelhardt, todavía no podemos observar en cuanto criterio central la visión del paciente como fuente de autoridad, sino que más bien apunta a la conveniencia de que el médico obtenga el consentimiento de éste para el beneficio mismo del tratamiento. ${ }^{27}$

En el mismo orden, encontramos la fundamentación de la decisión en el caso Carpenter vs. Blake, de 1878, en el que la Suprema Corte de Nueva York se pronunció señalando que la información era necesaria para que el paciente pudiera tener una recuperación exitosa, y que el médico era responsable por haber omitido dicha información, ${ }^{28}$ pudiendo observar que el motivo de dicha responsabilidad era precisamente desde el punto de vista médico del beneficio del paciente, no desde el punto de vista del respeto a la libertad y autonomía del mismo como elemento ético central en el ejercicio de la profesión médica, incluso al grado de considerarse que la omisión de obtener el consentimiento constituye en sí una mala práctica de la medicina.

Es así que se configura el concepto legal de battery como una posible conducta antijurídica por parte del personal de salud, que es el contacto dañino u ofensivo, que puede constituir un daño desde el punto de vista civil (tort) o desde el punto de vista penal (crime), y que incluye no haber obtenido el consentimiento para llevar a cabo el contacto.

También estos casos abonan elementos para la configuración de la negligencia, conducta antijurídica descrita en términos generales como la falta de cuidado que genera riesgos o daños a terceros; es decir, incumplir con el deber primario que tenemos todos los integrantes de la sociedad de actuar con prudencia y cuidado, que es la base del ejercicio de las acciones por responsabilidad civil, e incluso penal, y que además, para el caso de quienes actúan en el ejercicio de su profesión, requiere conducirse conforme a los estándares que ésta establece desde el punto de vista técnico y ético, siendo que se entiende que no obtener el consentimiento del paciente es una omisión o acción negligente por parte del médico.

\footnotetext{
27 "This decision is not grounded in a view of the patient as the source $f$ authority, but rather in concerns regarding why it World be usefu/ to gain consent", Engelhardt, Tristam, The Foundations of Bioethics, 2a. ed., Nueva York, Oxford University Press, 1996, p. 303.

${ }^{28}$ Faden, Ruth R. y Beauchamp, Tom L., A History and Theory of Informed Consent, Nueva York, Oxford University Press, 1986, pp. 117 y 118.
} 
Fue bajo esta lógica que empezó a desarrollarse la jurisprudencia estadounidense sobre la materia. En 1905, la Corte de Minnesota resolvió el caso Mohr vs. Williams, dando la razón a Anna Mohr, quien perdió el oído izquierdo a consecuencia de una operación para la que sólo había consentido la intervención en el oído derecho. En 1906, la Corte de Illinois resolvió el caso Pratt vs. Davis, a favor de la señora Davis a quien se le realizó una histerectomía sin su consentimiento, y en 1913 en Oklahoma se falló a favor de Mattie Strain, a quien en el curso de la atención de un absceso en un pie se le extrajo un pequeño hueso en contra de su voluntad expresa. ${ }^{29}$

Estas sentencias fueron el primer paso para someter la actividad del médico en relación con los pacientes al consentimiento de éstos, más allá de lo que el médico considere como lo más adecuado para la salud el paciente, según se expresó con claridad en la sentencia del caso Pratt vs. Davis.

Bajo un gobierno libre, el mayor y primer derecho de un individuo, que subordina a todos los demás, es el derecho a la inviolabilidad de su persona; ese derecho prohíbe a un médico, no importa cuán hábil o eminente sea, a violar sin permiso la integridad de su cuerpo para una operación importante colocándolo bajo anestesia a esos efectos. ${ }^{30}$

Finalmente, en 1914 se presentó el caso más conocido y considerado el triunfo definitivo en el reconocimiento del derecho del paciente a tomar decisiones en general en relación con su atención médica. Nos referimos a la conocida resolución del tribunal de Nueva York, en el caso Schloendorf vs. The Society of New York Hospital, en la cual dio la razón a Mary Berry Gamble, a quien se le realizó una operación sin su consentimiento, que además trajo graves consecuencias a su salud.

El juez Benjamín Cardozo pasó a la historia puesto que su resolución consolidó al principio de respeto a la autonomía como central en el ámbito biomédico y clínico, y como piedra angular de la relación médico-paciente, estableciendo expresamente el derecho que tiene toda persona adulta, en pleno uso de sus facultades mentales, a determinar lo que habrá de hacerse en su propio cuerpo, y cualquier médico que realiza un procedimiento, proporcione tratamiento o realice cualquier acto (médico) sin el consentimiento de su paciente, es sujeto de responsabilidad.

\footnotetext{
${ }^{29}$ Idem.

${ }^{30}$ Idem.
} 
Esta revista forma parte del acervo de la Biblioteca Jurídica Virtual del Instituto de Investigaciones Jurídicas de la UNAM

Y si bien, por diversas razones, el resultado del juicio no fue finalmente favorable a la demandante en tanto que no recibió la indemnización que solicitaba, e incluso tuvo que pagar las costas, la doctrina sentada por el juez Cardozo es la base del desarrollo doctrinal y jurisprudencial posterior en los Estados Unidos en relación con la obligación del médico de respetar la voluntad del paciente respecto de su atención médica: “Every human being of adult years and sound mind has a right to determine what shall be done with his own body; and a surgeon who performs an operation without his patient's consent, commits an assault, for which he is liable in damages". ${ }^{31}$

Aquí, subraya Engelhardt, es de notarse que el juez Cardozo reconoce el derecho a la autodeterminación sobre el propio cuerpo en el ámbito biomédico a aquellos sujetos con capacidad de decisión desde el punto de vista "racional", y no lo establece como un derecho de todo individuo a ser libre de intervenciones por parte de terceros sin legítima justificación, lo que él denomina the right to be left alone, y que a su juicio se configura en la jurisprudencia más adelante con casos como Olmstead vs. United States, decidido en 1928 por la Suprema Corte de Justicia en relación con la intervención de comunicaciones telefónicas para la obtención de pruebas dentro del proceso judicial, en donde el juez Louis D. Brandeis emitió su voto disidente en el sentido siguiente:

The protection guaranteed by the Amendments is much broader in scope. The makers of our Constitution undertook to secure conditions favorable to the pursuit of happiness. They recognized the significance of man's spiritual nature, of his feelings, and of his intellect. They knew that only a part of the pain, pleasure and satisfactions of life are to be found in material things. They sought to protect Americans in their beliefs, their thoughts, their emotions and their sensations. They conferred, as against the Government, the right to be let alone -- the most comprehensive of rights, and the right most valued by civilized men. To protect that right, every unjustifiable intrusion by the Government upon the privacy of the individual, whatever the means employed, must be deemed a violation of the Fourth Amendment. $^{32}$

31 El texto completo de la opinión del juez Cardozo puede verse en http://www.bioethics.gr/media/pdf/biolaw/nomologia/SCHLOENDORFFFULL.pdf.

32 El texto de la sentencia puede ser consultado en línea en el portal web https://supreme.justia.com/cases/federal/us/277/438/case.html), véase Engelhardt, Tristam, The Foundations of Bioethic, 2a. ed., Nueva York, Oxford University Press, 1996, pp. 304-306. El criterio establecido en el precedente de Olmstead fue superado por la decisión en el caso Katz vs. United States de 1967. 
Lo que el caso Schloendorffestablece en forma definitiva es el derecho que tienen los pacientes, en su calidad de sujetos autónomos, a decidir sobre su atención médica. No obstante, es relevante mencionar que dicha resolución todavía no arrojaba un estándar en cuanto a la calidad y cantidad de la información - que debemos considerar elemento fundamental al hablar hoy en día de consentimiento informado, y en sentido más amplio del respeto a la autonomía-.

El reconocimiento del derecho a contar con información suficiente para tomar decisiones, y el alcance de la obligación correspondiente por parte del médico, fue materia de la resolución emitida en 1972 por la Corte de Apelaciones de los Estados Unidos en el caso Canterbury vs. Spence, que versaba sobre un paciente que no fue informado de que el procedimiento que se había practicado implicaba un mínimo riesgo de parálisis.

El juez Spotswood W. Robinson, del circuito del distrito de Columbia, reconoce que generalmente el paciente tiene poco o nulo conocimiento sobre cuestiones médicas, por lo que requiere información para poder tomar una decisión, lo que obliga al médico no solamente a reconocer su derecho a decidir o rechazar atención médica, tratamientos y/o procedimientos, sino también su derecho a recibir la información que le permita tomar esa decisión. Respecto del derecho a recibir, determinó que no es posible - por ser, desde su punto de vista irrealista, irrazonable, e incluso innecesario en ciertos casos - adherirse al estándar de full disclosure, esto es, el despliegue de absolutamente toda la información con la que cuenta el médico. En relación con ello, existen diversos estándares que habían sido empleados con regularidad con respecto al despliegue de información, en cuanto a la calidad y cantidad de la misma: el de la buena práctica médica, el de la persona razonable, o bien basado en la costumbre de la comunidad médica.

No obstante, el juez Robinson estableció:

In our view, the patient's right of self-decision shapes the boundaries of the duty to reveal... The scope of the physician's communications to the patient, then, must be measured by the patient's need, and that need is the information material to the decision. 
Esta revista forma parte del acervo de la Biblioteca Jurídica Virtual del Instituto de Investigaciones Jurídicas de la UNAM

Thus the test for determining whether a particular peril must be divulged is its materiality to the patient's decision: all risks potentially affecting the decision must be unmasked. ${ }^{33}$

Es de notarse que el criterio ya se aparta del estándar beneficentista: debe revelarse al paciente todo aquello que pudiera influir en su decisión, y no solamente lo que pudiera ser benéfico para su salud. En tal sentido, la Corte delinea la obligación del médico de conocer las necesidades informativas de su paciente a efecto de que éste pueda tomar una decisión:

Consonantly with orthodox negligence doctrine, the physician's liability for nondisclosure is to be determined on the basis of foresight, not hindsight; no less than any other aspect of negligence, the issue of nondisclosure must be approached from the viewpoint of the reasonableness of the physician's divulgence in terms of what he knows or should know to be the patient's informational needs... He cannot know with complete exactitude what the patient would consider important to his decision, but on the basis of his medical training and experience he can sense how the average, reasonable patient expectably would react. ${ }^{34}$

No obstante, como se mencionó con anterioridad, el deber de desplegar información fue impuesto desde el universo ético-jurídico a la ética médica. Es por ello que hay críticos de la confianza que los jueces manifiestan en su vaguedad y en el amplio margen que dan al criterio del médico para que conforme a su experiencia y sensibilidad a las necesidades del paciente determine los alcances de su deber de informar. Dice Jay Katz:

The legal doctrine remained limited in scope, in part, because judges believed or wished to believe that their pronouncements on informed consent gave legal force to what good physicians customarily did; therefore they felt that they could defer the disclosure practices of "reasonable medical practitioners". Judges did not appreciate how deeply rooted the tradition of silence was and thus did not recognize the revolutionary, alien implications of their appeal for patient "self determination. ${ }^{35}$

Por lo anterior, debemos avanzar a estándares cada vez más objetivos en relación con la calidad y cantidad de información que debe proporcionarse al sujeto, y hacia un paradigma de la medicina que se aleje del paternalismo y del enfoque puramente

\footnotetext{
${ }^{33}$ Extracto de la resolución emitida el 19 de mayo de 1972, en Beauchamp, Tom L. y Walters, Leroy, Contemporary Issues in Bioethics, cit., pp. 384 y 385.

${ }^{34}$ Idem.

${ }^{35}$ Katz, Jay, "Physicians and Patients: a History of Silence", en Beauchamp, Tom L. y Walters, Leroy, Contemporary Issues in Bioethics, 1989, p. 387.
} 
Esta revista forma parte del acervo de la Biblioteca Jurídica Virtual del Instituto de Investigaciones Jurídicas de la UNAM

beneficentista, moviéndonos a una cultura de los derechos, en donde el médico es pieza clave. Es fundamental que éste se involucre de manera activa e integre la noción de respeto a la autonomía como principio fundamental en la práctica de su profesión y en su relación con el paciente, aprendiendo a entablar un verdadero diálogo. No obstante, no debemos perder de vista que el deber de respetar la autonomía va más allá de la toma de decisiones en equipo, que es ideal si nos circunscribimos al ámbito meramente clínico, en donde el conocimiento del médico, su experiencia y orientación alimentan la comprensión, la confianza, la participación y evidentemente la decisión verdaderamente autónoma del paciente. ${ }^{36}$

Ruth Faden y Tom Beauchamp ${ }^{37}$ consideran que el consentimiento informado no está restringido únicamente a la relación médico-paciente ni al ámbito clínico, sino que es aplicable a todo el espectro del ámbito biomédico, como puede ser la experimentación -incluso aquella que se realiza fuera del campo estrictamente biomédico, como son las ciencias sociales - que involucre la participación de sujetos humanos, sobre todo dado el contexto en que la bioética surge a raíz de la posguerra, que da pie al surgimiento de los derechos humanos, que generaliza y consolida a un nivel casi sacramental el deber de respeto a la autonomía de las personas en el sentido más amplio posible.

\section{EL RESPETO A LA AUTONOMÍA EN LA BIOÉTICA}

Es de todos conocido el brutal, sangriento y cruel escenario que fue la Segunda Guerra Mundial, el conflicto armado más grande de la historia de la humanidad, en el que participaron 70 países y se libraron combates en todos los ámbitos posibles, por tierra,

\footnotetext{
${ }^{36}$ Esta visión fue sostenida por la President's Comisión for the Study of Ethical Problems in Medicine and Biomedical and Behavioral Research, expresamente en el documento Making Health Care Decisions de 1982: "The Commission, while recognizing the difficulty of the task, relieves that 'shared decisionmaking' is the appropriate ideal for patient-professional relationships that a sound doctrine of informed consent should support... The health professional's expert knowledge, focused through the particular diagnosis and prognosis for the patient, usually confers on that person the natural role of leader and initiator in building this shared understanding. The patient, on the other hand, is especially well placed to asses the overall effects of the medical condition and possible treatments, in light of his or her own particular goals and values. Thus each party bring to the relationship special knowledge and perspectives that can help to clarify for both parties what is actually at issue in any decision to be reached", en Beauchamp, Tom L. y Walters, Leroy, op. cit., pp. 390 y 391.

37 “The Concept of Informed Consent”, en Beauchamp, Tom L. y Walters, Leroy, op. cit., pp. 394-398.
} 
Esta revista forma parte del acervo de la Biblioteca Jurídica Virtual del Instituto de Investigaciones Jurídicas de la UNAM

mar y aire. Conflicto al que además del horror de la guerra, que implicó la muerte de alrededor de 60 millones de personas, que correspondían al 2\% de la población mundial, deben sumarse las aberraciones cometidas por el nazismo en los campos de concentración destinados al exterminio de los judíos y de todos los pueblos o grupos que consideraban peligrosos o inferiores, y en donde, con Josef Mengele a la cabeza, se permitió que se llevaran a cabo seudoexperimentos brutalmente crueles en los prisioneros, sin ninguna justificación científica posible, y que parecían destinados más que a obtener algún conocimiento valioso a humillar y denigrar al enemigo, además de constituir el cruel divertimento de un verdadero enfermo mental, constituyendo el genocidio más grande e impactante de la historia de la humanidad. ${ }^{38}$

Una vez terminada la guerra, las 26 potencias vencedoras acordaron en Londres en 1945, constituir un tribunal militar ad hoc, con la finalidad de enjuiciar a los líderes de dicho régimen responsables de tan atroces conductas. El tribunal se instaló en la ciudad de Nüremberg, Alemania, precisamente la ciudad en la que se aprobaron las leyes del III Reich. Como resultado de los llamados juicios de Nüremberg, se redactaron diez principios básicos, que deben tenerse en cuenta para realizar experimentos en seres humanos, que se conocen como el Código de Nüremberg.

El Código reconoce en su primer punto, como uno de los principios fundamentales, la obligación de obtener y respetar el consentimiento voluntario del sujeto humano, así como sus salvaguardas, considerándolo como absolutamente esencial:

El consentimiento voluntario del sujeto humano es absolutamente esencial. Esto quiere decir que la persona afectada deberá tener capacidad legal para consentir; deberá estar en situación tal que pueda ejercer plena libertad de elección, sin impedimento alguno de fuerza, fraude, engaño, intimidación, promesa o cualquier otra forma de coacción o amenaza; y deberá tener información y conocimiento suficientes de los elementos de la materia envuelta para permitirle tomar una decisión correcta. Este último elemento exige que, antes de aceptar una respuesta afirmativa por parte de un sujeto experimental, el

\footnotetext{
${ }^{38} \mathrm{Al}$ respecto puede verse el documento de Moshe Sherist, "Médicina en la era nazi", en http://www.yadvashem.org/yv/es/education/presentations/medicina_nazi.pdf, así como Ortega Tamez, Luis Carlos, "Josef Mengele 'el ángel de la muerte' (1911-1979)", Evidencia Médica e Investigaciones en Salud, vol. 6, núm. 2, abril-junio de 2013, pp. 71 y 72; Posner, Gerald L. and John Ware, Mengele: the Complete Story, Nueva York, McGraw-Hill Book Company, 1986; Arendt, Hannah, Eichman in Jerusalem. A Reporto on the Banality of Evil, Nueva York, The Viking Press, 1965.
} 
investigador tiene que haberle dado a conocer la naturaleza, duración y propósito del experimento; los métodos y medios conforme a los que se llevará a cabo; los inconvenientes y riesgos que razonablemente pueden esperarse; y los efectos que para su salud o personalidad podrían derivarse de su participación en el experimento.

De este modo, el Código de Nüremberg reconoció y extendió la exigencia del consentimiento de las personas ya no en el campo de la atención médica, sino en esa otra importante esfera de la posible actividad del médico, como lo es la investigación científica en el área médica; dejando claro que el sujeto experimental es igualmente un ser humano cuya dignidad debe ser respetada también en el ámbito de la investigación científica, así como la obligación del investigador de asegurarse del conocimiento amplio de la persona sobre el experimento en el que va participar y sobre las posibles consecuencias que podría acarrearle.

Es especialmente relevante la inclusión que se hace en el Código, de la necesidad y exigencia de que la persona que participa en una investigación tenga la información adecuada y completa sobre los alcances, los métodos, los resultados que se esperan obtener $y$, por supuesto, de los riesgos y las consecuencias que puede implicar el experimento mismo, pues como dice el brocardo nihil volitum quem praecognitum, esto es, si la persona no cuenta con la información adecuada y suficiente, difícilmente podrá externar su voluntad con libertad.

En este proceso no puede dejar de tomarse en cuenta la Declaración Universal de los Derechos Humanos, adoptada por la Asamblea General de la Naciones Unidas el 10 de diciembre de 1948, dado que, como señalamos arriba, en gran medida el desarrollo del respeto a la voluntad y la autonomía del paciente se fundamenta en el desarrollo de la teoría de los derechos humanos y, evidentemente, con el impulso de su proceso de internacionalización, iniciado precisamente con la Declaración Universal, que en su artículo 10. establece que "Todos los seres humanos nacen libres e iguales en dignidad y derechos $y$, dotados como están de razón y conciencia, deben comportarse fraternalmente los unos con los otros".

Sin embargo, no fue sino hasta 1957 cuando la concepción del "consentimiento voluntario", en tanto obligación del médico para proceder en cualquier tratamiento, se reconoció en un texto jurídico como "consentimiento informado", imponiendo así la obligación al médico de informar debidamente al paciente, constituyéndose un verdadero derecho del paciente a la información. Esto fue desarrollado, una vez más, en 
Esta revista forma parte del acervo de la Biblioteca Jurídica Virtual del Instituto de Investigaciones Jurídicas de la UNAM

la jusrisprudencia estadounidense a partir del caso Salgo vs. Leland Stanford Junior University Board of Trustees, de donde se desprende la noción moderna del consentimiento informado, que implica la obligación del médico no sólo de obtener el consentimiento, sino de informar de modo adecuado al paciente, ${ }^{39}$ pues de otro modo el médico se expone a incurrir en responsabilidades, como expresamente lo señaló el juez al resolver el caso: “...los médicos violan sus deberes con sus pacientes y se exponen a demandas si se ocultan hechos que son necesarios para formar la base de un consentimiento informado inteligente por el paciente respecto al tratamiento propuesto". ${ }^{40}$

El tribunal estableció que el médico viola su obligación de informar al paciente, y que será sujeto de responsabilidad si retiene cualquier hecho o dato que se considere necesario para que el paciente pueda tomar una decisión. Reconoció “que dado que el estado mental y emocional es importante, en ciertos casos se debe ser discreto al discutir los diversos riesgos, siendo todo ello coherente con la información total de los hechos necesarios para un consentimiento informado", ${ }^{41}$ lo que se conoce como privilegio terapéutico; ${ }^{42}$ es decir, cuando la comunicación de dicha verdad puede tener repercusiones en el estado físico del paciente al grado de ponerlo en peligro. ${ }^{43}$

A partir de entonces se entiende al consentimiento informado como "la obligación legal que tiene el médico de informar a su paciente de todos los riesgos y beneficios

${ }^{39}$ Abellán, Fernando y Javier Sánchez-Cano, Consentimiento informado (parte 1), Madrid, Fundación Salud, 2000, pp. 22 y 23.

${ }^{40}$ Collazo, Eliseo, “Consentimiento informado en la práctica médica. Fundamentos bioéticos y aspectos prácticos", Cirugía Especializada, vol. 71, núm. 6, 2002, p. 320.

${ }^{41}$ Abellán, Fernando y Javier Sánchez-Cano, op. cit., p. 22.

${ }^{42}$ Figura que fue introducida en la práctica médica en 1972, con el caso Canterbury vs. Spence, según el cual “El médico tiene un privilegio terapéutico que le capacita para ocultarle información al paciente respecto de los riesgos del procedimiento al que va a ser sometido en el caso de que fuera evidente que un reconocimiento médico por un profesional juicioso demostrara que tal revelación supondría una grave amenaza para la integridad sicológica del paciente". Vázquez Ferreira, Roberto, "El consentimiento informado en la práctica médica", en http://www.sideme.org/doctrina/articulos/ci-ravf.pdf, pp. 5 y 6.

${ }^{43}$ Esto puede considerarse, como apunta Diego Gracia, una actitud paternalista, puesto que se informa o se deja de informar tomando en cuenta lo que le hace bien al paciente y no su derecho a saber y a decidir libre e informadamente. Gracia, Diego, op. cit., pp. 152 y 153. 
ligados al tratamiento o a la intervención propuesta, para que decida de acuerdo con su criterio"; 44 es decir, "la necesidad de dar al paciente una información completa sobre su enfermedad, el posible desarrollo, el plan terapéutico, las alternativas posibles, los riegos y beneficios, etcétera, para que el paciente pueda estar en condiciones de ejercer su autonomía y tomar las decisiones que le corresponden". ${ }^{45}$

El médico tiene el deber de dar al paciente la información más idónea y completa sobre su estado, teniendo en cuenta su nivel cultural, emotividad y capacidades de discernimiento. Esto se debe a que uno de los elementos de una decisión autónoma es que sea tomada de manera libre de toda coacción y con el conocimiento necesario para ello, es decir, que la persona autónoma debe actuar y decidir de manera autónoma. En este sentido, al derecho de la persona de autodeterminarse se corresponde el deber del médico de informar al paciente la verdad sobre su condición, los cursos de acción entre los cuales puede elegir sus consecuencias, de manera que cuente con los medios para poder adoptar una decisión, esto es, que pueda actuar de forma autónoma.

De este modo, no solamente se debe sancionar la falta de obtención del consentimiento informado como malpraxis o negligencia médica, sino que es una violación directa a los derechos del paciente. La negligencia en la información se equipara a la negligencia en la actuación, no obtener el consentimiento es coacción, y obtenerlo dando información insuficiente será negligencia, puesto que la finalidad es que el paciente tenga los elementos suficientes para tomar una decisión.

Esto quiere decir que el médico ya no puede elegir hasta dónde informar en razón de lo que considera prudente terapéuticamente, sino que debe hacerlo con la finalidad de que cualquier persona razonable pueda tomar una decisión, de acuerdo con el criterio establecido en 1969 por la Corte de Apelación de California en el caso Berkley vs. Anderson. $^{46}$

Otro instrumento importante es la Declaración de la Asociación Médica Mundial sobre los Principios Éticos para las Investigaciones Médicas en Seres Humanos de 1964,

\footnotetext{
${ }^{44}$ Abellán, Fernando y Javier Sánchez-Cano, op. cit., p. 9.

${ }^{45}$ Lucas Lucas, Ramón, “Testamento vital y consentimiento informado", Explícame la bioética, Madrid, Ediciones Palabra, 2005, pp. 205-212. Puede verse en línea en http://biblio.upmx.mx/download/cebidoc/Dossiers/ortotanasia0111.asp.

${ }^{46}$ El texto de la sentencia puede verse en $h t t p: / / w w w . / a w l i n k . c o m / r e s e a r c h / C a s e L e v e / 3 / 47330$.
} 
Esta revista forma parte del acervo de la Biblioteca Jurídica Virtual del Instituto de Investigaciones Jurídicas de la UNAM

conocida como la Declaración de Helsinki, y sus revisiones posteriores, ${ }^{47}$ que tomando como antecedente el Código de Nüremberg estableció algunas figuras novedosas para la obtención del consentimiento destinados a la participación en proyectos de investigación, como es el caso del representante legal para los casos de incapaces e inhábiles física o mentalmente (párrafo 24), o la obligación de recabar el consentimiento de los menores que sean capaces sicológicamente, además del consentimiento del representante legal (párrafo 25).

En 1966, Henry K. Beecher, profesor de anestesiología de la Universidad de Harvard, conmocionó a la comunidad médica y a la sociedad estadounidense con un artículo publicado en New England Journal of Medicine, ${ }^{48}$ en el cual presentó 22 casos de experimentos en seres humanos, específicamente con personas pertenecientes a grupos vulnerables como niños, personas con alguna discapacidad, personas de la tercera edad y grupos raciales minoritarios, realizados en los Estados Unidos y financiados con dinero público, que no cumplían con las normas y principios éticos aplicables a la investigación clínica.

El texto de Beecher provocó un verdadero shock, por la similitud de los casos que presentaba con los abusos cometidos por los nazis, además de que los proyectos eran financiados con recursos públicos, ${ }^{49}$ por lo que surgió la necesidad de la creación de nuevos códigos deontológicos más estrictos para la investigación clínica en seres humanos.

Así, en 1973 la Asociación Americana de Hospitales aprobó la Patient's Bill of Rights, en la cual se desarrolla lo relativo al derecho a la información y al consentimiento. Este

\footnotetext{
47 29a. Asamblea Médica Mundial, Tokio, Japón, octubre de 1975; 35a. Asamblea Médica Mundial, Venecia, Italia, octubre 1983; 41a. Asamblea Médica Mundial, Hong Kong, septiembre de 1989; 48a. Asamblea General Somerset West, Sudáfrica, octubre 1996; 52a. Asamblea General, Edimburgo, Escocia, octubre de 2000; Nota de Clarificación del Párrafo 29, agregada por la Asamblea General de la AMM, Washington 2002; Nota de Clarificación del Párrafo 30, agregada por la Asamblea General de la AMM, Tokio 2004; 59a. Asamblea General, Seúl, Corea, octubre de 2008.

48 El texto del artículo de Beecher, traducido al castellano, puede verse en http://www.icf.uab.es/icbdigital/docs/beecher.pdf.

${ }^{49}$ Drave, James F., op. cit., p. 23.
} 
Esta revista forma parte del acervo de la Biblioteca Jurídica Virtual del Instituto de Investigaciones Jurídicas de la UNAM

derecho al consentimiento informado ya no debe considerarse parte del derecho a la salud (beneficentista) sino como un derecho aislado (autonomicista). De este modo

...se empezaba a utilizar un lenguaje nuevo, el de los derechos, mucho más propio de una ética basada en el principio de autonomía. Aunque no pueda ni deba exagerarse la comparación, cabe decir que el lenguaje de la virtud ha sido el principio de la ética médica beneficentista, y el de los derechos lo es el de la ética médica basada en el principio de autonomía. ${ }^{50}$

Por otro lado, en 1978, con base en los trabajos de la National Comission for the Protection of Human Subjects of Biomedical and Behavioral Research, el Departamento de Salud, Educación y Bienestar de los Estados Unidos redactó un informe, en el cual se establecieron los principios básicos de respeto a la autonomía, beneficencia y justicia, como rectores en toda decisión de bioética, así como los requisitos mínimos del consentimiento informado, conocido como el Informe Belmont, debido a que las reuniones de la Comisión se llevaron a cabo en el Centro de Conferencias de Belmont, en el que se sentaron las bases para el desarrollo de la llamada bioética de principios o principialista.

Esta bioética principialista fue desarrollada como método de deliberación en bioética por Tom L. Beuchamp y James F. Childress. En relación con la autonomía, los autores sostienen:

To respect autonomous agents is to acknowledge their right to hold views, to make choices, and to take actions base don their personal values and beliefs...Respect, in this account, involves acknowledging the value and decision-making rights of persons and enabling then to act autonomously, whereas disrespect for autonomy involves attitudes and actions that ignore, insult, disdain, or are inattentive to other's rights of autonomous actions. ${ }^{51}$

El principio de respeto a la autonomía, según Beauchamp y Childress, desde el punto de vista del sujeto, implica, en primer lugar, que todos los individuos deben ser tratados como agentes autónomos $\mathrm{y}$, segundo, que todas las personas cuya autonomía está disminuida, como es el caso de los menores de edad o los incapaces, tienen derecho a protección.

\footnotetext{
${ }^{50}$ Gracia, Diego, op. cit., p. 177.

${ }^{51}$ Beauchamp, Tom L. y Childress, James F., op. cit., p. 99.
} 
La autonomía en las decisiones, desde el punto de vista del acto, debe reunir los requisitos de intencionalidad, conocimiento y ausencia de control externo. La intencionalidad no admite grados, puesto que se tiene o no en su totalidad, pero tanto el conocimiento como el control externo pueden darse de manera gradual, pudiendo ser más o menos autónoma una decisión.

Una acción será intencional cuando es querida de acuerdo con un plan, puede ser que sea deseado o tolerado, pero al fin y al cabo querido. El conocimiento se relaciona directamente con la información que se posee. El control externo puede ir desde la coerción, la manipulación y la persuasión, y debe entenderse separado de la intencionalidad.

Se habla también de una autenticidad; es decir, que no haya problemas de control interno en el individuo que va a tomar una decisión, y que las conductas realizadas por el individuo o las decisiones que tome no contradigan el sistema de valores que sostiene esa persona.

El principio de beneficencia se refiere a que el médico deberá actuar siempre de acuerdo con lo que sea mejor para el paciente; sin embargo, el principio de beneficencia no debe inhibir al principio de autonomía; es decir, que debe entenderse este principio en sentido no paternalista. El paternalismo es el rechazo a los deseos, opciones y acciones de otra persona "por su propio bien"; es decir "el rechazo a aceptar o a consentir los deseos, opciones y acciones de las personas que gozan de información suficiente y de capacidad o competencia adecuada, por el propio beneficio del paciente". ${ }^{52}$ Una beneficencia no paternalista es entonces la que busca hacer el bien hasta donde el paciente lo pide o lo acepta.

Por ello, si bien el principio de no maleficencia -complementario al principio de beneficencia - establece que nunca será legítimo hacer el mal, el principio de autonomía establece que no siempre es legítimo hacer el bien. ${ }^{53}$ El principio de beneficencia debe estar entonces acotado por el consentimiento informado.

52 Gracia, Diego, op. cit., p. 102.

53 El médico ya no puede querer la beneficencia de modo paternalista, sino que debe renunciar a este principio como absoluto y entender que debe articularse con los principios de autonomía y justicia, que se encuentran en un mismo nivel para ser ponderados. No deben lesionarse los principios de autonomía y 
Con el desarrollo del consentimiento informado se da un cambio de paradigma, que define que los principios de beneficencia y de no maleficencia, e incluso el de justicia, deben someterse al principio de autonomía, en tanto que son expresión de la dignidad de la persona; esto es, del trato que el individuo debe recibir de los demás de acuerdo con su condición de ser humano, como lo planteó Giovanni Pico de la Mirandola desde el siglo XVIII. ${ }^{54}$

La justicia, que es el tercer principio básico en las decisiones bioéticas y de ética médica, es aportado por las terceras partes a la relación médico-paciente. Si las terceras partes están ausentes en la relación, se pondera solamente entre autonomía y beneficencia. Es importante que este principio entre a la ponderación, puesto que los problemas bioéticos no solamente afectan a los individuos, sino a la sociedad en su conjunto. En este sentido, se habla de una moral civil o social; es decir, de una moral colectiva, que corresponde a los valores aceptados o reconocidos en cada grupo social, y que debe ser preservada por el Estado, pero sin ser estática e inamovible, sino siempre adaptándose a los cambios paradigmáticos y axiológicos que la sociedad vaya enfrentando.

De este modo, el derecho a la información y al consentimiento informado se han desarrollado como un derecho autónomo, complementario al derecho a la salud, con lo que podemos concluir que si bien la persona tiene derecho a que el Estado proteja su salud, proporcionándole los servicios adecuados para que pueda alcanzarla y preservarla, también tiene derecho a decidir sobre la manera en que habrá de disfrutar de esos derechos; es decir, que podrá elegir dónde y de qué manera tratar su enfermedad o condición y, de este modo, el Estado está obligado a respetar esa decisión y a proporcionarle los medios para asegurarle ese respeto. Uno de los objetivos del consentimiento informado fue precisamente promover la autonomía del paciente, que

justicia con la finalidad de actuar conforme al principio de beneficencia, siempre deberá ponderarse en el caso concreto.

${ }^{54}$ Vale la pena rescatar la visión de la autonomía de Pico de la Mirandola, en su momento casi revolucionaria, centrada en la concepción del hombre como un ser casi todo potencia, y por tanto merecedor de admiración y respeto por su capacidad de autodeterminarse. De la Mirandola, Pico, De la dignidad del hombre, Madrid, Editora Nacional, 1984. 
Esta revista forma parte del acervo de la Biblioteca Jurídica Virtual del Instituto de Investigaciones Jurídicas de la UNAM

es su fundamento moral; además de que desde la década de los noventa, la autonomía se considera una de las dimensiones clave de la calidad de vida de los pacientes. ${ }^{55}$

Hoy en día el concepto de consentimiento ha evolucionado, en parte gracias a la doctrina jurisprudencial estadounidense, de la exigencia de un consentimiento simple para actuar sobre un individuo:

...en el que era suficiente con el asentimiento del paciente una vez informado de la naturaleza esencial e intención del procedimiento propuesto, a la exigencia de que el paciente obtenga una información más amplia que la anterior, en la que se incluyan un balance adecuado sobre los riesgos y beneficios que dicho procedimiento comporta, así como las alternativas al tratamiento con sus correspondientes beneficios y riesgos. En la actualidad se acepta que tratar a un paciente sin su consentimiento o pese a sus objeciones puede constituir una agresión ilegal (battery), mientras que el tratamiento tras un consentimiento informado incorrecto se considera propiamente una práctica inadecuada (malpractice). ${ }^{56}$

Así, el respeto a la libertad de la persona y a los derechos de los pacientes adquieren “...una especial relevancia en el marco de las relaciones asistenciales, ámbito en el que la autonomía de la persona constituye un elemento central cuyas manifestaciones más evidentes, pero no exclusivas, se plasman en la necesidad de suministrar información y de recabar el consentimiento de las personas enfermas". ${ }^{57}$

La edición de 1984 del Manual de ética del Colegio de Médicos Americanos define al consentimiento informado de la siguiente manera:

El consentimiento informado consiste en la explicación a un paciente atento y normalmente competente de la naturaleza de su enfermedad, así como del balance entre los efectos de la misma y los riesgos y beneficios de los procedimientos terapéuticos recomendados, para a continuación solicitarle su aprobación para ser sometido a esos procedimientos. La presentación de la información al paciente debe ser comprensible y no sesgada; la

\footnotetext{
${ }^{55}$ Verdugo, Miguel A. y Martín, Mónica, “Autodeterminación y calidad de vida en salud mental: dos conceptos emergentes", Salud Mental, México, Instituto Nacional de Psiquiatría Ramón de la Fuente, vol. 25, núm. 4, agosto del 2002, p. 70.

${ }^{56}$ Abellán, Fernando y Sánchez-Cano, Javier, op. cit., p. 29.

57 "Documento de voluntades anticipadas”, Acta bioética, año VII, núm. 1, Grupo del Observatorio de Bioética y Derecho de la Universidad de Barcelona, España, 2001, p. 1.
} 
colaboración del paciente debe ser conseguida sin coerción; el médico no debe sacar partido de su potencial dominancia sicológica del paciente. ${ }^{58}$

Es por ello que hoy entendemos el concepto de consentimiento informado como "la obligación legal que tiene el médico de informar a su paciente de todos los riesgos y beneficios ligados al tratamiento o a la intervención propuesta, para que decida de acuerdo con su criterio". 59

Como podemos apreciar, dos problemas centrales en el ámbito de la bioética clínica actual, que aportan a la pregunta ¿qué puedo/debo hacer como médico?, son la información (qué informar, a quién informar, y cómo informar) y la decisión (qué decidir, quién decide). Lo anterior, sumergidos, claro está, en la complejidad de nuestra realidad como sociedad plural, donde convergen diversas perspectivas, cosmovisiones, tradiciones, culturas, religiones e incluso lenguajes, no solamente desde el punto de vista técnico -que para los médicos es muy evidente-, sino también ético.

En México, si bien no existe una ley especialmente dedicada a normar el consentimiento informado, el mismo está ampliamente regulado mediante las reformas y adiciones que se han formulado tanto a la Ley General de Salud (LGS) ${ }^{60}$ como a distintos reglamentos de la misma, y con la expedición de diversas normas oficiales, en las que se regula para prácticas o grupos específicos, y de manera más general en la norma oficial relativa al expediente clínico; además de que tanto el consentimiento informado como el derecho a decidir sobre la propia atención médica, el derecho a la confidencialidad en la relación médico-paciente y el derecho a obtener una segunda opinión, todos fundados en la autonomía personal, fueron incluidos en la Carta de Derechos Generales de los Pacientes, que fue presentada en diciembre de 2001 por el presidente de la República.

Concluimos aquí con esta primera parte, puntualizando como tema relevante la manera en que el derecho y el desarrollo de la figura del consentimiento informado en la jurisprudencia anglosajona, especialmente la estadounidense, vino a constituirse en un elemento de rescate a la relación médico-paciente, que se encontraba ceñida a la óptica

\footnotetext{
${ }^{58}$ Vázquez Ferreira, Roberto, op. cit., p. 3.

${ }^{59}$ Abellán, Fernando y Javier Sánchez-Cano, op. cit., p. 9.

${ }^{60}$ Artículo 77 bis 37, fracciones V, VIII y IX.
} 
del paternalismo clásico, que hizo crisis con el desarrollo de las ideas liberales potenciadoras del respeto a la dignidad y la autonomía humanas.

En este sentido, la figura jurídica del consentimiento informado es hoy asumida en la medicina como parte esencial de la praxis médica, y ha servido para dar un nuevo marco a la relación entre el enfermo, y el médico, que ya no sólo se preocupa por sanar el cuerpo del enfermo sino por garantizar el mayor bienestar posible a la persona que se pone en sus manos confiando en sus conocimientos.

Con esto se enriquece el principio de beneficencia, de profunda raigambre en la ética médica desde el juramento hipocrático, como vimos arriba, con el principio de justicia, que va más al reconocimiento de la condición de persona del enfermo, que asume por medio de este instrumento jurídico el control sobre la forma en que es atendido en sus enfermedades; todo esto sin menoscabar la dignidad profesional del médico, que es precisamente quien informa y orienta al paciente para que pueda tomar sus decisiones, lo que se vuelve especialmente relevante cuando esas decisiones se refieren a la forma en que se quiere vivir el final de la vida.

\section{BIBLIOGRAFÍA}

ABELLÁN, Fernando y SÁNCHEZ-CANo, Javier, Consentimiento informado (parte 1), Madrid, Fundación Salud 2000, 2000.

ABELLÁN, Fernando y SÁNCHEZ-CARO, Javier (coords.), Medicina genética clínica del siglo XXI. Consideraciones científicas, éticas y legales, Madrid-Granada, Comares, 2009.

Barquín Calderón, Manuel, Historia de la medicina, 8a. ed., México, Méndez Editores, 2007.

Beauchamp, Tom L. y Childress, James F., Principles of Biomedical Ethics, 6a. ed., Nueva York, Oxford Univesity Press, 2009.

- - - y Walters, Leroy, Contemporary Issues in Bioethics, 3a. ed., Estados Unidos, Wadsworth Publishing Company, 1989.

BINETTI, Paola, "Más allá de consentimiento informado: la relación consensual", Cuadernos de Bioética, AEBI, vol. XXII, núm. 76, septiembre-diciembre, 2011.

CAMPAGNE, Fabián Alejandro, “Medicina y religión en el discurso antisupersticioso español de los siglos XVI a XVIII: un combate por la hegemonía", Dynamis: acta hispanica ad 
Esta revista forma parte del acervo de la Biblioteca Jurídica Virtual del Instituto de Investigaciones Jurídicas de la UNAM

medicinae scientiarumque historiam illustrandam, Granada, Universidad de Granada, núm. 20, 2000.

CANo Valle, Fernando y Moreno SÁnChez, José Antonio, “El consentimiento bajo información ¿un documento o un proceso?", Segundas Jornadas sobre Globalización y Derechos Humanos: Bioética y Biotecnología, México, UNAM, 2004.

Collazo, Eliseo, “Consentimiento informado en la práctica médica. Fundamentos bioéticos y aspectos prácticos", Cirugía Especializada, vol. 71, núm. 6, 2002.

CARRIÓn GARCÍA, Yazmín Yadira, Derecho: fines y alcances desde la perspectiva de Fernando Savater, México, Porrúa-Facultad de Derecho UNAM, 2013, versión Kindle.

COMité INTERNACIONAL DE BioÉTICA, Report of the International Bioethics Committee on Consent, París, UNESCO, 2008.

CONAMED, Consentimiento válidamente informado, México, CONAMED, 2004.

DRAVE, James F., "La ética como carácter y la investigación médica”, Acta Bioethica, Organización Panamericana de la Salud, año X, vol. X, núm. 1, 2004.

EngelhardT, Tristam, The Foundations of Bioethics, 2a. ed., Nueva York, Oxford University Press, 1996.

Faden, Ruth R. y Beauchamp, Tom L., A History and Theory of Informed Consent, Nueva York, Oxford University Press, 1986.

Frondizi, Rizieri, Introducción a los problemas del hombre, 2a. ed., México, Fondo de Cultura Económica, 2004.

García Morente, Manuel, Lecciones preliminares de filosofía, 18a. ed., México, Porrúa, 2005.

Gracia, Diego, Fundamentos de bioética, 3a. ed., Madrid, Triacastela, 2008.

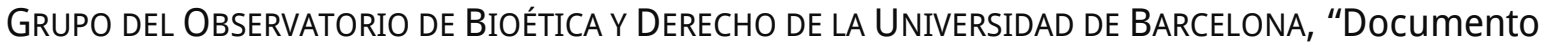
de voluntades anticipadas", Acta Bioética, año VII, núm. 1, España, 2001.

LUCAS LUCAS, Ramón, “Testamento vital y consentimiento informado", Explícame la bioética, Madrid, Ediciones Palabra, 2005.

MILL, John S., Sobre la libertad, 5a. ed., México, Gernika, 2006.

Mirandola, Pico de la, De la dignidad del hombre, Madrid, Editora Nacional, 1984. 
Esta revista forma parte del acervo de la Biblioteca Jurídica Virtual del Instituto de Investigaciones Jurídicas de la UNAM

NogueirA, Roberto P., “La medicina liberal y el mercado de trabajo en salud ¿qué es la medicina liberal?", Revista Educación Médica y Salud, vol. 22, núm. 2, 1988.

O'SHEA, Tom, Consent in History, Theory and Practice, the Essex Autonomy Proyect, University of Essex, 2011, puede verse en http://autonomy.essex.ac.uk/consent-inhistory-theory-and-practice.

PAVÍA-Ruz, Norma et al., “Magia, religión y medicina”, Revista Biomédica, núm. 9, 1998.

PÉREZ Fuentes, Gisela María y Domínguez, Karla Cantoral, “El consentimiento informado como garantía constitucional desde la perspectiva del derecho mexicano", Revista de Derecho Privado, nueva época, año V, núm 15, septiembre-diciembre de 2006.

Romeo CASABONA, Carlos María, “El consentimiento informado en la relación entre el médico y el paciente: aspectos jurídicos", Problemas prácticos del consentimiento informado, Barcelona, Cuadernos de la Fundación Víctor Grífols i Lucas, núm, 5, 2002.

SCHNEEWIND, Jerome B., La invención de la autonomía. Una historia de la filosofía moral moderna, México, Fondo de Cultura Económica, 2009.

SimÓN LORDA, Pablo, "Diez mitos en torno al consentimiento informado", Anales del Sistema Sanitario de Navarra, vol. 19, suplemento 3, 2006.

Verdugo, Miguel A. y Martín, Mónica, “Autodeterminación y calidad de vida en salud mental: dos conceptos emergentes", Salud Mental, México, Instituto Nacional de Psiquiatría Ramón de la Fuente, vol. 25, núm. 4, agosto 2002.

Páginas de Internet

http://wWw. elabe.bioetica.org/34.htm.

http://eticabioetica.obolog.com/rol-leyes-codigos-eticos-practica-clinica-215346.

http://www.diariosalud.net/content/view/13793/2/.

http://WWw.bioethics.gr/media/pdf/biolaw/nomologia/SCHLOENDORFFFULL.pdf.

https://supreme.justia.com/cases/federal/us/277/438/case.htm/.

http://WWW.sideme.org/doctrina/articulos/ci-ravf.pdf.

http://www.lawlink.com/research/CaseLeve/3/47330.

http://wWw.icf.uab.es/icbdigital/docs/beecher.pdf. 